\title{
Nicotinic Acetylcholine Receptors and Cardiac Vagal activity in Rats with Type 2 Diabetes

\author{
Jinxu Liu" ${ }^{1 \#, ~ D o n g z e ~ Z h a n g ~}{ }^{1 \#}$, Huiyin Tu${ }^{1}$, Robert L Muelleman ${ }^{1}$, Wei-Zhong Wang ${ }^{2}$ and Yu-Long Li $i^{13^{*}}$
}

${ }^{1}$ Department of Emergency Medicine, University of Nebraska Medical Center, Omaha, NE 68198, USA

${ }^{2}$ Department of Physiology, Second Military Medical University, Shanghai 200433, People's Republic of China

${ }^{3}$ Department of Cellular and Integrative Physiology, University of Nebraska Medical Center, Omaha, NE 68198, USA

\#These authors contributed equally to this work

\begin{abstract}
Reduced cardiac parasympathetic activity is involved in sudden cardiac death and is responsible for high mortality in patients with type 2 diabetes mellitus (T2DM). Nicotinic acetylcholine receptors (nAChRs) mediate synaptic transmission in the intracardiac ganglia (ICG) and regulate the excitability of postganglionic parasympathetic neurons. We hypothesized that changes in the functional responsiveness of postsynaptic nAChRs to nicotine (a nAChR agonist) might be involved in attenuated cardiac parasympathetic (vagal) activity in type 2 diabetic rats. A rat model of T2DM was induced by a combination of both high-fat diet and injection of low-dose streptozotocin $(30 \mathrm{mg} / \mathrm{kg}$, i.p.). As an index of cardiac vagal function, changes of heart rate in response to graded vagal efferent nerve stimulation were blunted in T2DM rats, compared to sham rats. In isolated Langendorff-perfused hearts, there was no significant difference on sensitivity of the heart to acetylcholine in sham and T2DM rats. Whole-cell patch-clamp data showed that T2DM decreased nAChR currents and sensitivity of the nAChR channel to nicotine in ICG neurons. However, the data from immunofluorescence staining showed that there is no significant difference in the protein expression of $\alpha 3$ and $\beta 4 \mathrm{nAChR}$ subunits in ICG neurons of sham and T2DM rats. These results suggest that the low sensitivity of nAChR channels to nicotine might contribute to impairment of the cardiac vagal activity in T2DM.
\end{abstract}

Keywords: Cardiac vagal activity; Intracardiac ganglion; Ion channels; Type 2 Diabetes Mellitus

\section{Introduction}

Cardiovascular autonomic dysfunction is a common complication of the patients with type 2 diabetes mellitus (T2DM) [1-5], which is associated with a higher risk of sudden cardiac death in T2DM patients $[1,4,6]$. Unlike type 1 diabetes mellitus, the mechanisms responsible for the cardiovascular autonomic dysfunction have not been explored in T2DM even though T2DM affects 90 to $95 \%$ of the diabetic population worldwide [7] compared to 5 to $10 \%$ affected by type 1 diabetes mellitus. Data from one research group demonstrated that function of the parasympathetic nervous system is severely affected in T2DM patients [2].

Furthermore, our recent study also found that the neuronal excitability of cardiac vagal efferent neurons located in the intracardiac ganglia (ICG) was reduced due to a reduced number of the voltagegated $\mathrm{Ca}^{2+}$ channels in T2DM rats [8], a T2DM animal model that closely mimics the clinical features of T2DM patients [9]. In general, cardiac vagal preganglionic fibers originated in the brainstem (nucleus ambiguous and nucleus tractus solitaries) extend to the ICG and release acetylcholine ( $\mathrm{ACh}$, a primary neurotransmitter) to process the synaptic transmission and regulate the excitability of cardiac vagal postganglionic neurons through activating nicotinic ACh receptors (nAChRs) of ICG neurons [10-12]. The nAChR is a member of ligand-gated ion channels on the cell membrane [13-15]. As inotropic receptors, $\mathrm{nAChR}$ channels are activated by endogenous and exogenous agonists such as acetylcholine and nicotine $[14,15]$. Therefore, the first aim in this study was to test whether diabetes changes the sensitivity of nAChR channels to nicotine in ICG neurons.

As a final common pathway for neural control of the cardiac function, cardiac vagal postganglionic neurons innervate the heart to form the neuroeffector junction. ACh released from cardiac vagal postganglionic neurons binds and activates muscarinic ACh receptors on the myocardial cell membrane to regulate the heart function. It is possible that sensitivity of the heart to ACh can affect the regulatory effect of the cardiac parasympathetic nervous system on the heart. Therefore, the second aim in this study was to compare sensitivity of the heart to ACh between sham and T2DM rats.

\section{Materials and Methods}

All experimental procedures were approved by the University of Nebraska Medical Center Institutional Animal Care and Use Committee and were carried out in accordance with the National Institutes of Health (NIH Publication No. 85-23, revised 1996) and the American Physiological Society's Guides for the Care and Use of Laboratory Animals.

\section{Induction of T2DM}

Male Sprague-Dawley rats (200-220 g) were housed two per cage under controlled temperature and humidity and a 12-h:12-h dark/light cycle. Water and rat chow were provided ad libitum. The rats were randomly assigned to sham $(n=18)$ and T2DM rats $(n=23)$. In sham group, the rats were fed a normal chow diet consisting of $13 \%$ fat, $53 \%$ carbohydrate, and 34\% protein (Harlan Teklad sterilizable rodent diet; Harlan Teklad, Madison, WI). T2DM was induced by a combination of high-fat diet and streptozotocin (STZ) treatment as previously described [8]. First, the rats were fed a high-fat diet consisting of $42 \%$ fat, $42.7 \%$ carbohydrate, and $15.2 \%$ protein (Harlan Teklad adjusted fat diet, Harlan Teklad) for 4 weeks. Next, the rats were intraperitoneally injected with STZ $(30 \mathrm{mg} / \mathrm{kg})$ and continued on the high-fat diet.

*Corresponding author: Yu-Long Li, MD, Ph.D, Department of Emergency Medicine, University of Nebraska Medical Center, Omaha, NE 68198-5850, USA Tel: 1-402-559-3016; Fax: 1-402-559-9659; E-mail: yulongli@unmc.edu

Received June 19, 2015; Accepted July 15, 2015; Published July 20, 2015

Citation: Liu J, Zhang D, Tu H, Muelleman RL, Wang WZ, et al. (2015) Nicotinic Acetylcholine Receptors and Cardiac Vagal activity in Rats with Type 2 Diabetes. Diabetes Metab S13: 012. doi:10.4172/2155-6156.S13-012

Copyright: ( 2015 Liu J, et al. This is an open-access article distributed unde the terms of the Creative Commons Attribution License, which permits unrestricted use, distribution, and reproduction in any medium, provided the original author and source are credited. 
Fasting blood glucose and body weight in all rats were measured weekly. All experiments were performed at 12-14 weeks of feeding with either normal chow diet or high-fat diet because our previous study revealed the characteristics of T2DM (hyperlipidemia, insulin resistance, and hyperglycemia) [8]. As we did in our previous studies $[8,16]$, T2DM was identified by measuring fasting blood glucose, plasma insulin, plasma triglyceride and insulin sensitivity on the day of terminal experiments. Additionally, body weight, blood pressure, and heart rate were measured. Five rats in T2DM group were excluded from study because they were not considered as T2DM.

\section{Measurement of plasma insulin, plasma triglyceride and insulin sensitivity}

Blood samples for insulin and triglyceride analyses were collected in tubes coated with EDTA and stored at $-80^{\circ} \mathrm{C}$ until assayed. Plasma insulin was assessed by ELISA kits (ALPCO, Salem, NH) and plasma triglyceride level was measured by triglyceride spectrophotometric assay kit (BioVision, Mountain View, CA), according to the manufacturer's instructions. Both blood glucose and insulin were used to calculate the insulin sensitivity index as Ln (fasting blood glucose $\times$ fasting plasma insulin level $)^{-1}$.

\section{Measuring alteration of heart rate in response to vagal efferent nerve stimulation}

Under anesthetized condition $(800 \mathrm{mg} / \mathrm{kg}$ urethane and $40 \mathrm{mg} /$ $\mathrm{kg}$ chloralose, i.p.), tracheotomy was performed, and the rat was artificially ventilated by a mechanical respirator (Harvard Apparatus, $2.5 \mathrm{ml}$ tidal volume and $60 \mathrm{breath} / \mathrm{min}$ ). A polyethylene- 50 catheter was implanted into the femoral artery for the measurement of arterial blood pressure and heart rate. Both sides of vagal nerve along the common carotid arteries were isolated and cut. The peripheral end of right vagal nerve was placed on bipolar stimulating electrodes and covered by mineral oil for vagal efferent nerve stimulation. Right vagal efferent nerve stimulation was applied using a Grass S9 stimulator (Grass instruments, Quincy, MA) with $10 \mathrm{~s}$ of constant-frequency stimulation $(0.1 \mathrm{~ms}$ pulse duration and intensity of $7.5 \mathrm{~V}, 1-100 \mathrm{~Hz})$. Changes in heart rate related to different stimulating frequency were recorded by PowerLab 8/30 data acquisition system with LabChart 7 (ADInstruments, Colorado Springs, $\mathrm{CO}$ ), which was used as the index of cardiac vagal function.

\section{Measuring sensitivity of the heart to $\mathrm{ACh}$ in isolated Langendorff perfused heart model}

Under anesthetized condition $(50 \mathrm{mg} / \mathrm{kg}$ sodium pentobarbital, i.p.), the rat was treated with heparin (1000 U/kg, i.p.). The animal heart was removed rapidly via midsternal thoracotomy and placed in an icecold $\mathrm{Ca}^{2+}-\mathrm{Mg}^{2+}$ free-Tyrode's solution $(140 \mathrm{mM} \mathrm{NaCl}, 5 \mathrm{mM} \mathrm{KCl}, 10$ $\mathrm{mM}$ HEPES and $5 \mathrm{mM}$ glucose; $\mathrm{pH}$ 7.2). After the aorta was cannulated, the animal heart was mounted on a Langendorff apparatus (Radnoti, Monrovia, CA) and perfused with oxygenated Krebs-Hensleit solution composed of $124 \mathrm{mM} \mathrm{NaCl}, 4.8 \mathrm{mM} \mathrm{KCl}, 1.8 \mathrm{mM} \mathrm{CaCl}_{2}, 1 \mathrm{mM}$ $\mathrm{MgSO}_{4}, 1.2 \mathrm{mM} \mathrm{KH}_{2} \mathrm{PO}_{4}, 20 \mathrm{mM} \mathrm{NaHCO}$ and $10 \mathrm{mM}$ glucose $(\mathrm{pH}$ 7.4 when gassed with $95 \% \mathrm{O}_{2} / 5 \% \mathrm{CO}_{2}$ ). The flow rate was maintained at $11.0 \pm 0.5 \mathrm{ml} / \mathrm{min}$. Temperature of the solution was kept at $37^{\circ} \mathrm{C}$. After two electrodes were attached to the right atrium and apex, the electrocardiogram was continuously recorded using a PowerLab 8/30 Data Acquisition system with LabChart 7 software (ADInstruments, Colorado Springs, CO). After equilibration for $60 \mathrm{~min}$, ACh (0.01-30 $\mu \mathrm{M} ; 0.1 \mathrm{ml}$ ) was directly applied into the heart through the perfusate with 15-min interval between ACh applications.

\section{Isolation of ICG neurons}

The ICG was removed surgically from the rat and placed in an icecold modified Tyrode's solution (mM): $140 \mathrm{NaCl}, 5 \mathrm{KCl}, 10 \mathrm{HEPES}$, 5 glucose. The ICG was minced into small pieces with microscissors and incubated for $30 \mathrm{~min}$ at $37^{\circ} \mathrm{C}$ in an enzymatic modified Tyrode's solution containing $0.1 \%$ collagenase and $0.1 \%$ trypsin. The tissue was then transferred to a modified Tyrode's solution containing $0.2 \%$ collagenase and $0.5 \%$ bovine serum albumin for $30 \mathrm{~min}$ of incubation at $37^{\circ} \mathrm{C}$. The isolated cells were resuspended in culture medium and plated onto culture wells. The culture medium consisted of a 50/50 mixture of Delbecco's modified Eagle's medium (DMEM) and Ham's F12 medium (Gibco, Grand Island, NY) supplemented with antibiotics and $10 \%$ fetal bovine serum (Gibco, Grand Island, NY). ICG neurons were cultured at $37^{\circ} \mathrm{C}$ in a humidified atmosphere of $95 \%$ air $/ 5 \% \mathrm{x} \mathrm{CO}$ for $4-8 \mathrm{hr}$ before the experiments.

\section{Whole cell patch-clamp recordings for $\mathrm{nAChR}$ currents}

A gap-free protocol was used for the recording of nAChR currents in whole-cell voltage-clamp experiments. The recording of $\mathrm{nAChR}$ currents was performed using an Axopatch 200B patch-clamp amplifier (Axon Instruments, Foster City, CA). Resistance of the patch pipette was 3-5 $\mathrm{M} \Omega$ when filled with the solution composed of (in $\mathrm{mM}$ ): 140 $\mathrm{CsCl}, 2 \mathrm{MgATP}, 10$ HEPES, and 1 EGTA (pH 7.2, $300 \mathrm{mOsm} / \mathrm{L}$ ). The extracellular solution consisted of (in $\mathrm{mM}$ ): $140 \mathrm{NaCl}, 3 \mathrm{KCl}, 2.5 \mathrm{CaCl}_{2}$, $1.2 \mathrm{MgCl}_{2}, 10 \mathrm{HEPES}$, and 7.7 glucose ( $\mathrm{pH} 7.2 ; 310 \mathrm{mOsm} / \mathrm{L}$ ). Series resistance of 6-13 $\mathrm{M} \Omega$ was electronically compensated $80-90 \%$. Junction potential was calculated to be $+5.1 \mathrm{mV}$. Recorded traces were sampled at $10 \mathrm{kHz}$ and filtered at $5 \mathrm{kHz}$. ICG neurons were clamped at $-90 \mathrm{mV}$ and continuously perfused with extracellular solution $(2 \mathrm{ml} / \mathrm{min})$. Nicotine, a nAChR specific agonist dissolved in the extracellular solution was applied to ICG neurons by bolus ejection (6 psi; $100 \mathrm{~ms}$ ) through a micropipette connected to a Picopump (PV 820 Pneumatic PicoPump, World Precision Instruments, Sarasota, FL). The micropipette (5-7 $\mu \mathrm{m}$ diameter) for drug application was positioned 20-30 $\mu \mathrm{m}$ from the cell soma. No current was observed when the extracellular solution alone was applied to ICG neurons (data not shown). Each nicotine concentration from $0.1 \mu \mathrm{M}$ to $10 \mathrm{mM}$ was applied 2 times to obtain a mean data. The 90 -sec interval was left between drug applications of each concentration to allow $\mathrm{nAChR}$ recovery from desensitization. Peak currents were measured, and current density was calculated by dividing peak current by cell membrane capacitance. Additionally, to rule out the influence of nAChR current rundown, we applied 10 $\mathrm{mM}$ of nicotine to ICG neurons at the beginning and the ending of above experiments and compared nAChR currents during these two applications of nicotine. There was no significant rundown of $n A C h R$ currents in most of ICG neurons (data not shown). There were a few neurons to be excluded from the study due to the obvious rundown of nAChR currents. P-clamp 10.2 program (Axon Instruments) was used for data acquisition and analysis. All experiments were done at room temperature $\left(22-24^{\circ} \mathrm{C}\right)$.

\section{Immunofluorescent staining for $\mathrm{nAChR}$ proteins}

Isolated ICG neurons plated onto coverslips were fixed with $4 \%$ paraformaldehyde in $0.1 \mathrm{M}$ PBS for $10 \mathrm{~min}$ at $4^{\circ} \mathrm{C}$, washed with PBSTriton solution (phosphate-buffered saline $+0.25 \%$ Triton X-100), and blocked with $10 \%$ of normal goat serum for $1 \mathrm{~h}$ at room temperature. Primary antibodies against $\mathrm{nAChR} \alpha 3$ or $\mathrm{nAChR} \beta 4$ (R\&D, Las Vegas, 
NV) and PGP9.5 (a neuronal marker; Abcam, Cambridge, MA) were incubated with ICG neurons overnight at $4^{\circ} \mathrm{C}$. Then ICG neurons were incubated with appropriate secondary antibodies (Invitrogen, Carlsbad, CA) for $1 \mathrm{~h}$ at room temperature. ICG cells were observed under a Leica fluorescent microscope with appropriate excitation/ emission filters. Pictures were captured by a digital camera system. No staining was seen when PBS was used instead of the primary antibody in above procedure. Expression of $n A C h R ~ \alpha 3$ and $\beta 4$ subunits was quantified using Adobe Photoshop CS3 Extended (Adobe Systems Incorporated, CA)[17].

\section{Data analysis}

The concentration-response relationships for reduction of heart rate by $\mathrm{ACh}$ and nicotine-triggered $\mathrm{nAChR}$ current were drawn by a logistic equation: $\mathrm{y}=\min +(\max -\min ) /\left(1+\left(\mathrm{x} / \mathrm{EC}_{50}\right)^{\text {Hillslope }}\right)$, where $\min$ is the minimum effect and max is the maximum effect, $\mathrm{EC}_{50}$ is the drug concentration that yields $50 \%$ of the maximum effect, and Hillslope is the slope factor. All data are presented as means \pm SE. SigmaPlot 12 was used for data analysis. Student's unpaired $t$-test or 2-way ANOVA with post hoc Bonferroni test was used to determine statistical significance. Statistical significance was accepted when $P<0.05$.

\section{Results}

\section{Induction of T2DM}

T2DM was induced by a combination of both high-fat diet and injection of low-dose STZ. After 12-14 weeks of the treatments (high-fat diet and STZ injection), fasting blood glucose and plasma triglyceride were increased whereas insulin sensitivity index was decreased in T2DM rats, compared with that in sham rats (Table 1). These data indicated that high-fat diet and low-dose STZ induced hyperglycemia, hyperlipidemia and insulin resistance in T2DM rats, which closely mimicked the pathogenesis and clinical characteristics of patients with T2DM [9]. However, there was no significant difference on body weight, blood pressure, heart rate, and fasting plasma insulin between sham and T2DM rats (Table 1).

\section{Effect of vagal efferent nerve stimulation on heart rate}

Changes in heart rate related to different stimulating frequency usually are used as the index of cardiac vagal function. Bradycardia response to graded electrical stimulation of vagal efferent nerve was significantly attenuated in T2DM rats, compared to sham rats (Figure 1).

\section{Effect of ACh on heart rate in Langendorff perfused hearts}

The negative chronotropic effect of ACh on Langendorff-perfused hearts isolated from sham and T2DM rats was studied. Diabetes did not induce change in the intrinsic heart rate, compared to sham (Figure 2A). Application of exogenous ACh dose-dependently decreased heart

Table 1: Hemodynamic and metabolic characteristics of sham and T2DM rats

\begin{tabular}{|c|c|c|}
\hline & Sham (n=18) & T2DM $(\mathbf{n = 1 8 )}$ \\
\hline Body weight, $\mathrm{g}$ & $409 \pm 8$ & $457 \pm 11^{*}$ \\
\hline Mean blood pressure, $\mathrm{mm} \mathrm{Hg}$ & $97 \pm 3$ & $102 \pm 4$ \\
\hline Heart rate, bmp & $354 \pm 10$ & $357 \pm 13$ \\
\hline Fasting blood glucose, $\mathrm{mg} / \mathrm{dl}$ & $92.7 \pm 4.9$ & $278.6 \pm 9.7^{*}$ \\
\hline Fasting plasma insulin, $\mathrm{mu} / \mathrm{L}$ & $12.4 \pm 1.3$ & $11.2 \pm 1.6$ \\
\hline Insulin sensitivity index & $-4.13 \pm 0.11$ & $-5.23 \pm 0.26^{*}$ \\
\hline Plasma Triglyceride, $\mathrm{mmol} / \mathrm{L}$ & $1.13 \pm 0.24$ & $3.57 \pm 0.36^{*}$ \\
\hline
\end{tabular}

Data are means $\pm S E$. ${ }^{*} P<0.05$ vs. sham. bmp: beats per minute

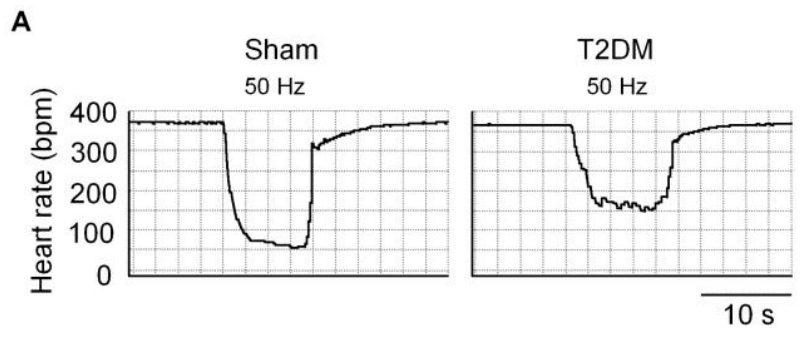

B

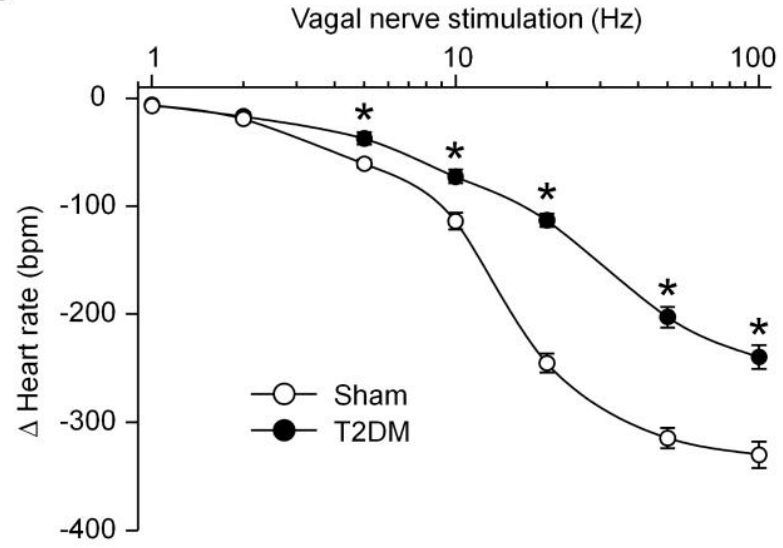

Figure 1: Representative recordings (A) and summary data (B) showing changes of heart rate in response to graded vagal efferent nerve stimulation in sham and T2DM rats. ${ }^{*} P<0.05$ vs. sham. Data are means $\pm S E, \mathrm{n}=6$ rats in each group.

\section{A}
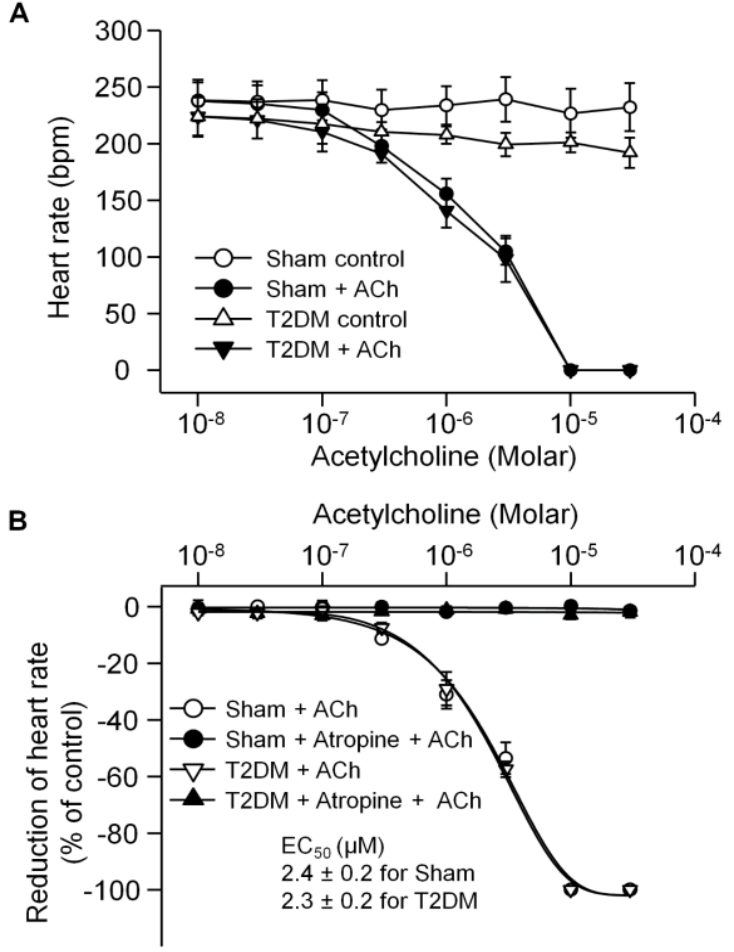

Figure 2: Heart rate $(A)$ and percent reduction of heart rate $(B)$ in response to different concentrations of acetylcholine (Ach) in isolated Langendorff-perfused hearts from sham and T2DM rats. In atropine plus ACh groups, $1 \mu \mathrm{M}$ atropine (a specific muscarinic acetylcholine receptor blocker) was co-applied with ACh to hearts. Data are means $\pm S E, n=6$ rats in each group. 
rate in sham and T2DM Langendorff perfused hearts. There was no marked difference on sensitivity of the heart to ACh $(2.4 \pm 0.2 \mu \mathrm{M}$ vs. $2.3 \pm 0.2 \mu \mathrm{M}$ for $\mathrm{EC}_{50}$ of $\mathrm{ACh}$ in sham and $\mathrm{T} 2 \mathrm{DM}$, respectively; $P>0.05$; Figure $2 \mathrm{~B})$. Application of atropine $(1 \mu \mathrm{M}$, a muscarinic $\mathrm{AChR}$ antagonist) completely abolished the negative chronotropic effect of $\mathrm{ACh}$ in sham and T2DM rats. However, atropine alone did not affect the heart rate (data not shown).

\section{nAChR currents in ICG neurons}

Figure $3 \mathrm{~A}$ illustrates original recordings of the nAChR currents elicited by bolus ejection of $3 \mathrm{mM}$ nicotine $(100 \mathrm{~ms})$ to the cell body of ICG neurons. The nAChR currents were significantly decreased in ICG neurons from $\mathrm{CHF}$ rats, compared with that from sham rats (Figure $3 \mathrm{~A}$ and $3 \mathrm{~B})$. Pre-treatment of hexamethonium $(100 \mu \mathrm{M}$, a nAChR antagonist) almost inhibited nAChR currents in both sham and T2DM ICG neurons (Figure 3A-B). The data from dose-dependent curve demonstrated that EC50 of nicotine to elicit the nAChR current was higher in ICG neurons from CHF rats $(229 \pm 22 \mu \mathrm{M})$ than that from sham rats $(159 \pm 17 \mu \mathrm{M} ; P<0.05$; Figure $3 \mathrm{C})$.

\section{Protein expression of $\mathbf{n A C h R s}$ in ICG neurons}

Our previous study has shown that western blot analysis is not used as an appropriate method to measure protein expression in the ICG because of limitation of the tiny ICG tissue [8]. Immunofluorescence staining was used to measure protein expression of $\mathrm{nAChR} \alpha 3$ and $\beta 4$ subunits in rat ICG neurons (nAChR- $\alpha 3 \beta 4$, a functional combination expressed in autonomic ganglia at high levels [18]. There was no significant difference in protein expression of $n A C h R ~ a 3$ and $\beta 4$ subunits in ICG neurons of sham and T2DM rats (Figure 4).

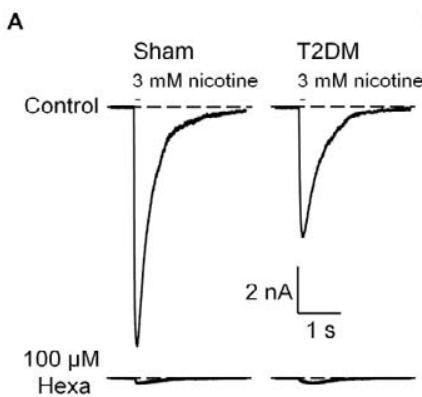

$\square$ Control

Control $+100 \mu \mathrm{M}$ Hexa

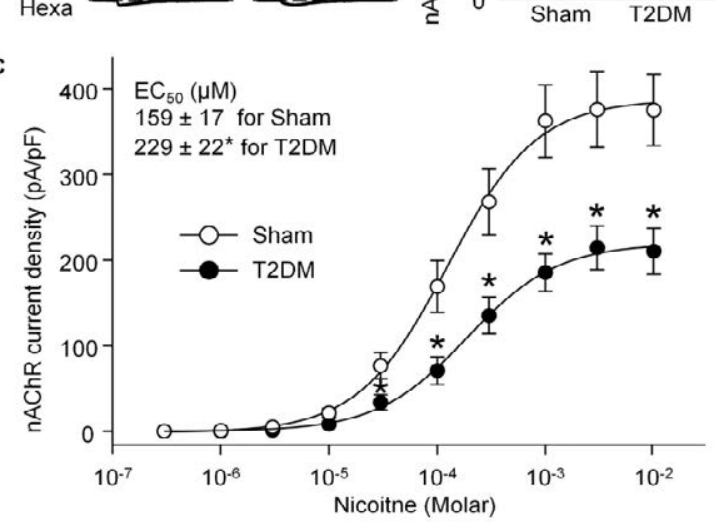

Figure 3: Original recordings $(A)$ and mean data $(B)$ of nicotine $(3 \mathrm{mM}$, $100 \mathrm{~ms})$-evoked $\mathrm{nAChR}$ currents before and after treatment of Hexa $(100 \mu \mathrm{M})$ in ICG neurons from sham and type 2 diabetic rats. ${ }^{*} P<0.05$ vs. sham control; ${ }^{\#} P<0.05$ vs. T2DM control. (C) Dose-response of nAChR current density to nicotine in ICG neurons from sham and T2DM rats. ${ }^{*} P<0.05$ vs. sham. Hexa: hexamethonium, a $n A C h R$ antagonist. Data are means $\pm S E, n=12$ cells in each group.

\section{Discussion}

Our present study demonstrated that 1) T2DM reduced the responsiveness of heart rate to vagal efferent nerve stimulation, but did not affect sensitivity of the heart to ACh;2) T2DM also decreased nAChR currents and the sensitivity of nAChR channels to nicotine in ICG neurons; and 3) T2DM did not change the protein expression of nAChR- $\alpha 3$ and $-\beta 4$ subunits in ICG neurons. These results suggest that cardiac vagal dysfunction could be attributed to the alteration in functional responsiveness of $\mathrm{nAChR}$ channels to neurotransmitter $(\mathrm{ACh})$ in ICG neurons rather than the change in sensitivity of the heart to ACh in T2DM rats.

Much evidence from clinical trials and animal experiments has shown that the blunted arterial baroreflex is a common complication in T2DM [1-5], which contributes to the electrical instability of the myocardium and is associated with high mortality in the T2DM state $[1,4,6]$. The arterial baroreflex arc is composed of a baroreceptor afferent limb, a central neural component, and autonomic efferent component. Although the morphological and functional changes in every component of the arterial baroreflex arc could be responsible for the impairment of baroreflex function in the T2DM state, a clinical study found that the parasympathetic nerve function is severely impaired in the patients with T2DM [2]. In the present study, negative chronotropic responses to graded vagal efferent nerve stimulation were attenuated in T2DM rats, compared to sham rats (Figure 1), indicating that the parasympathetic efferent component could be involved in the impaired arterial baroreflex in the T2DM state.

Besides the parasympathetic efferent component, changes of the heart itself may affect bradycardia response to the vagal efferent nerve stimulation. In our present study, T2DM did not change the intrinsic heart rate of isolated Langendorff- perfused rat hearts (Figure 2). More importantly, there is no difference in sensitivity of the heart to ACh between sham and T2DM rats (Figure 2). From above results, we consider that functional alterations of the postganglionic vagal neurons but not changes of the heart might contribute to the impairment of cardiac vagal activity in T2DM rats.

It is well documented that nAChRs, a sub-family of ligand-gated non-selective cation channels, mediate synaptic transmission in the peripheral autonomic ganglia $[12,19]$. On the postsynaptic membrane, activation of $\mathrm{nAChRs}$ by its agonists (such as $\mathrm{ACh}$ and nicotine) induces an inward current and eventually cause the terminal of postganglionic neurons to release neurotransmitter into the target organs [20-25]. In our present study, T2DM markedly decreased nAChR currents and the sensitivity of nAChR channels to nicotine in ICG neurons (Figure 3), which is probably involved in lower excitability of ICG neurons and blunted cardiac vagal activity in T2DM rats. Nevertheless, the role of nAChR channels in the attenuated cardiac vagal activity is further confirmed in future study by manipulating the function of $\mathrm{nAChR}$ channels in ICG neurons through pharmacological treatments or genetic methods.

Molecular clone technique has identified nine $\alpha(\alpha 2-\alpha 10)$ and three $\beta$ ( $\beta 2-\beta 4)$ gene subunits of neuronal nAChRs in the central and peripheral nervous system [24,25]. Exogenous expression studies in Xenopus oocytes demonstrated that many subunit combinations form functional pentameric nAChR channels [24-26]. Although the 
Citation: Liu J, Zhang D, Tu H, Muelleman RL, Wang WZ, et al. (2015) Nicotinic Acetylcholine Receptors and Cardiac Vagal activity in Rats with Type 2 Diabetes. J Diabetes Metab S13: 012. doi:10.4172/2155-6156.S13-012

Page 5 of 6

prevalent $\mathrm{nAChRs}$ in the mammalian brain contain homomeric $\alpha 7$ and heteromeric $\alpha 4 \beta 2$ subunits, a composition of $\alpha 3 \beta 4$ subunits is the predominant functional combination of the $\mathrm{nAChR}$ channel expressed in the peripheral autonomic ganglion neurons [27-31]. Additionally, single-cell RT-PCR data showed that $\alpha 3$ and $\beta 4$ subunit mRNAs are expressed in most of rat ICG neurons [32]. Immunofluorescence staining data showed that there is no significant difference in the protein expression of $n A C h R-\alpha 3$ and $-\beta 4$ subunits in ICG neurons of sham and T2DM rats (Figure 4), which indicates that T2DM-reduced nAChR currents are possibly due to the post-translational modulation of nAChR channels in ICG neurons from T2DM rats. However, we cannot rule out the involvement of other nAChR subunits because mRNAs encoding other neuronal $n A C h R$ subunits were also expressed in some rat ICG neurons [32]. Further study is needed to clarify the mechanism(s) responsible for T2DM-reduced nAChR currents in ICG neurons.

Ciccone et al. [33] have demonstrated the role of pre-diabetes and family history of diabetes mellitus in the outcome of general population. They have emphasized that it is very important to prevent the onset of the most dangerous lesions induced by diabetes [33]. Abnormal cardiac vaginal activity is thought to be a predictor of mortality in T2DM [1]. Therefore, the alteration of nAChR channels and cardiac vagal activity during pre-diabetes and the influence of family history of diabetes will be addressed in further study.

\section{Conclusions}

In the present study, we found that T2DM decreases nAChR currents and the functional responsiveness of $\mathrm{nAChR}$ channels to nicotine in ICG neurons. The reduced sensitivity of nAChR channels to nicotine in ICG neurons might be involved in the attenuated cardiac vagal activity in the T2DM state.

\section{Acknowledgements}

This study was supported by the National Institutes of Health's National Heart Lung, and Blood Institute grant HL-098503 (to Y.-L.L.)

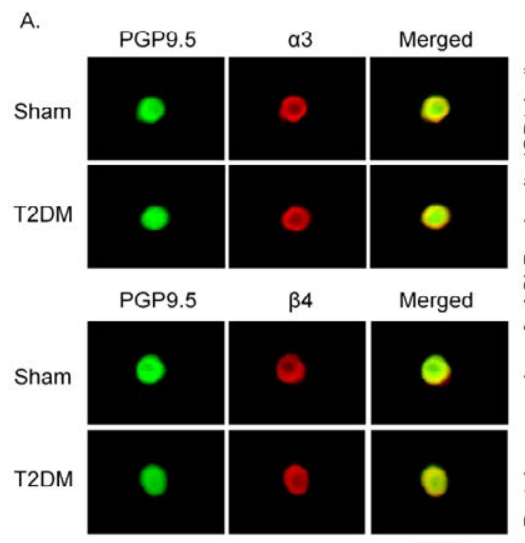

$50 \mu \mathrm{m}$

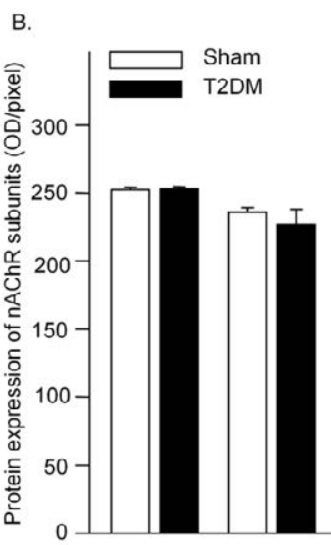

a3

$\beta 4$
Figure 4: Representative images $(A)$ and quantitative data $(B)$ for protein expression of $n A C h R-\alpha 3$ and $-\beta 4$ subunits in ICG neurons from sham and T2DM rats. PGP9.5: a neuronal marker. Data are mean \pm SE, $n=40$ cells from 4 rats in each group.

\section{Disclosures}

The authors declare that they have no conflict of interests regarding the publication of this paper.

\section{References}

1. Chen HS, Hwu CM, Kuo BI, Chiang SC, Kwok CF, et al. (2001) Abnormal cardiovascular reflex tests are predictors of mortality in Type 2 diabetes mellitus. Diabet Med 18: 268-273.

2. Freccero C, Svensson H, Bornmyr S, Wollmer P, Sundkvist G (2004) Sympathetic and parasympathetic neuropathy are frequent in both type 1 and type 2 diabetic patients. Diabetes Care 27: 2936-2941.

3. Ruiz J, Monbaron D, Parati G, Perret S, Haesler E, et al. (2005) Diabetic neuropathy is a more important determinant of baroreflex sensitivity than carotid elasticity in type 2 diabetes. Hypertension 46: 162-167.

4. Sanya EO, Brown CM, Dütsch M, Zikeli U, Neundörfer B, et al. (2003) Impaired cardiovagal and vasomotor responses to baroreceptor stimulation in type II diabetes mellitus. Eur J Clin Invest 33: 582-588.

5. Spallone V, Ziegler D, Freeman R, Bernardi L, Frontoni S, et al. (2011) Cardiovascular autonomic neuropathy in diabetes: clinical impact, assessment, diagnosis, and management. Diabetes Metab Res Rev 27: 639-653.

6. Maser RE, Mitchell BD, Vinik Al, Freeman R (2003) The association between cardiovascular autonomic neuropathy and mortality in individuals with diabetes: a meta-analysis. Diabetes Care 26: 1895-1901.

7. Souza BM, Assmann TS, Kliemann LM, Gross JL, Canani LH, et al. (2011) The role of uncoupling protein 2 (UCP2) on the development of type 2 diabetes mellitus and its chronic complications. Arq Bras Endocrinol Metabol 55: 239248

8. Liu J, Tu H, Zheng H, Zhang L, Tran TP, et al. (2012) Alterations of calcium channels and cell excitability in intracardiac ganglion neurons from type 2 diabetic rats. Am J Physiol Cell Physiol 302: C1119-1127.

9. Reaven GM (2011) Relationships among insulin resistance, type 2 diabetes essential hypertension, and cardiovascular disease: similarities and differences J Clin Hypertens (Greenwich) 13: 238-243.

10. Armour JA (2008) Potential clinical relevance of the 'little brain' on the mammalian heart. Exp Physiol 93: 165-176.

11. Olshansky B, Sabbah HN, Hauptman PJ, Colucci WS (2008) Parasympathetic nervous system and heart failure: pathophysiology and potential implications for therapy. Circulation 118: 863-871.

12. Thomas GD (2011) Neural control of the circulation. Adv Physiol Educ 35: 2832.

13. Lindstrom J (1997) Nicotinic acetylcholine receptors in health and disease. Mol Neurobiol 15: 193-222.

14. Gotti C, Clementi F (2004) Neuronal nicotinic receptors: from structure to pathology. Prog Neurobiol 74: 363-396.

15. Lindstrom JM (2003) Nicotinic acetylcholine receptors of muscles and nerves: comparison of their structures, functional roles, and vulnerability to pathology. Ann N Y Acad Sci 998: 41-52.

16. Zheng H, Liu X, Li Y, Mishra PK, Patel KP (2014) Attenuated dopaminergic tone in the paraventricular nucleus contributing to sympathoexcitation in rats with Type 2 diabetes. Am J Physiol Regul Integr Comp Physiol 306: R138-148.

17. Tu H, Zhang L, Tran TP, Muelleman RL, Li YL (2010) Diabetes alters protein expression of hyperpolarization-activated cyclic nucleotide-gated channel subunits in rat nodose ganglion cells. Neuroscience 165: 39-52.

18. De Biasi M (2002) Nicotinic mechanisms in the autonomic control of organ systems. J Neurobiol 53: 568-579.

19. Armour JA (1991) Intrinsic cardiac neurons. J Cardiovasc Electrophysiol 2 331-41.

20. Bibevski S, Zhou Y, McIntosh JM, Zigmond RE, Dunlap ME (2000) Functional nicotinic acetylcholine receptors that mediate ganglionic transmission in cardiac parasympathetic neurons. J Neurosci 20: 5076-5082.

21. Bibevski S, Dunlap ME (2004) Prevention of diminished parasympathetic control of the heart in experimental heart failure. Am J Physiol Heart Circ Physiol 287: H1780-1785. 
Citation: Liu J, Zhang D, Tu H, Muelleman RL, Wang WZ, et al. (2015) Nicotinic Acetylcholine Receptors and Cardiac Vagal activity in Rats with Type 2 Diabetes. J Diabetes Metab S13: 012. doi:10.4172/2155-6156.S13-012

Page 6 of 6

22. Fee JD, Randall WC, Wurster RD, Ardell JL (1987) Selective ganglionic blockade of vagal inputs to sinoatrial and/or atrioventricular regions. J Pharmacol Exp Ther 242: 1006-1012.

23. Dyavanapalli J, Rimmer K, Harper AA (2010) Reactive oxygen species alters the electrophysiological properties and raises $\left[\mathrm{Ca}^{2+}\right] \mathrm{i}$ in intracardiac ganglion neurons. Am J Physiol Regul Integr Comp Physiol 299: R42-54.

24. Albuquerque EX, Pereira EF, Alkondon M, Rogers SW (2009) Mammalian nicotinic acetylcholine receptors: from structure to function. Physiol Rev 89: 73-120.

25. Papke RL (2014) Merging old and new perspectives on nicotinic acetylcholine receptors. Biochem Pharmacol 89: 1-11.

26. Hogg RC, Raggenbass M, Bertrand D (2003) Nicotinic acetylcholine receptors: from structure to brain function. Rev Physiol Biochem Pharmacol 147: 1-46.

27. Perry DC, Xiao Y, Nguyen HN, Musachio JL, Dávila-García MI, et al. (2002) Measuring nicotinic receptors with characteristics of alpha4beta2, alpha3beta2 and alpha3beta4 subtypes in rat tissues by autoradiography. J Neurochem 82 : 468-481.

28. Park KS, Cha SK, Kim MJ, Kim DR, Jeong SW, et al. (2006) An alpha3beta4 subunit combination acts as a major functional nicotinic acetylcholine receptor in male rat pelvic ganglion neurons. Pflugers Arch 452: 775-783.

29. Mao D, Yasuda RP, Fan H, Wolfe BB, Kellar KJ (2006) Heterogeneity of nicotinic cholinergic receptors in rat superior cervical and nodose Ganglia. Mol Pharmacol 70: 1693-1699.

30. David R, Ciuraszkiewicz A, Simeone X, Orr-Urtreger A, Papke RL, et al (2010) Biochemical and functional properties of distinct nicotinic acetylcholine receptors in the superior cervical ganglion of mice with targeted deletions of nAChR subunit genes. Eur J Neurosci 31: 978-93.

31. Ciuraszkiewicz A, Schreibmayer W, Platzer D, Orr-Urtreger A, Scholze P, et al. (2013) Single-channel properties of alpha3beta4, alpha3beta4alpha5 and alpha3beta4beta2 nicotinic acetylcholine receptors in mice lacking specific nicotinic acetylcholine receptor subunits. J Physiol 591: 3271-88.

32. Poth K, Nutter TJ, Cuevas J, Parker MJ, Adams DJ, et al. (1997) Heterogeneity of nicotinic receptor class and subunit mRNA expression among individual parasympathetic neurons from rat intracardiac ganglia. J Neurosci 17: 586-596.

33. Ciccone MM, Scicchitano P, Cameli M, Cecere A, Cortese, et al. (2014) Endothelial function in pre-disbetes, diabetes and diabetic cardiomyopathy: a review. J Diabetes Metab 5: 364.
This article was originally published in a special issue, Type 2 Diabetes Mellitus- Disease, Diagnosis \& Treatment handled by Editors. Dr. Judit Bene, University of Pécs, Hungary; Eun Seok Kang, Yonsei University College of Medicine, Korea 